\title{
The Comparison of the Different Balance Performance of Soccer Players Versus Sedentary
}

\author{
Inci Kesilmis \\ Institute of Educational Sciences, Department of Physical Education and Sports, Mersin University, Mersin, Turkey
}

Email address:

incikesilmis@mersin.edu.tr

\section{To cite this article:}

Inci Kesilmis. The Comparison of the Different Balance Performance of Soccer Players Versus Sedentary. International Journal of Sports Science and Physical Education. Vol. 2, No. 3, 2017 pp. 37-43. doi: 10.11648/j.ijsspe.20170203.11

Received: June 11, 2017 Accepted: July 3, 2017 Published: July 31, 2017

\begin{abstract}
This study aims to compare different dynamic balance ability between soccer players and sedentary. Sixteen soccer players and 18 sedentary participated in the study. Soccer players group participated soccer trainings consisting of different coordinative exercises for 3 years; the sedentary group attended a normal school program. Soccer players' mean height was $157.81 \pm 6.63 \mathrm{~cm}$, mean weight was $44.06 \pm 6.81 \mathrm{~kg}$ and sedentary mean height was $154.91 \pm 7.45 \mathrm{~cm}$, mean weight was $43.46 \pm 7.03 \mathrm{~kg}$. Informed consent form signed by the entire participant, their parents and the trainer prior to the study as required by the Helsinki declaration. Dynamic balance ability with Prokin, Y balance and Flamingo balance tests were used. Factorial ANOVA and independent samples $t$ test was used for analyzing the results. For dynamic balance ability; bipedal perimeter length $(p=0.019)$, area gap percentage $(p=0.019)$ and medium speed $(p=0.032)$; right foot perimeter length $(p=0.03)$ and medium speed $(\mathrm{p}=0.03)$ values; and for $\mathrm{Y}$ balance; right anterior $(\mathrm{p}=0.001)$, left anterior $(\mathrm{p}=0.001)$, right posteriolateral $(p=0.001)$, left posteriolateral ( $p=0.008)$ measurements and also for flamingo balance test both on right-left foot and eyes openclosed results $(\mathrm{p} \leq 0.001)$ are significantly different in favor of soccer players. There were no significant difference for dynamic balance bipedal-right-left forward backward axis and medium lateral axis, right foot area gap percentage, left foot perimeter length, area gap percentage and medium speed and for y balance; right-left foot posteriomedial measurements. The dynamic balance ability of soccer players was clearly different than that of sedentary. According to these results it can be concluded that the effect of extensive soccer skill practice on overall balance control.
\end{abstract}

Keywords: Soccer, Dynamic Balance, Y Balance, Flamingo

\section{Introduction}

The successful yield of fundamental movement and sport skills takes the ability to stabilize the body and maintain dynamic balance [1]. In a situation of balance a technical gesture is more effective and easier to perform in many sports [2]. Balance (for the human body) is the ability to be zero of the sum of the forces acting on the body, gravitation of the body, protection of the sequence under the influence of internal and external forces [3]. Balance may be static when the body is either at rest (static balance) or dynamic when the body is in steady-state motion (dynamic balance) [4]. Dynamic balance is the ability to maintain stability while forecasting and reacting to alteration as the body moves through the infinite [5]. Static balance is the ability to stand with as little sway as possible. Standing balance can be evaluated in a resting state or following a specific inequality
[6]. While running with the ball to avoid being tackled by the opposition, soccer players require more of dynamic balance in order to change direction at different speed [4]. Furthermore, technical skills such as static, semi-dynamic and dynamic balance are required in soccer. Most of these technical skills like passing, juggling the ball, dribbling or receiving the ball, are accomplish through standing on one leg. In the intensive circumstances such as pushing rivals, slippery grass, changes to the ball's direction, moving etc., balance plays a considerable role [2]. Good balance that plays a substantial role in the soccer players' activities in the match is a high performance indicator in soccer [7]. Soccer players often perform shooting, lower extremity passing and dribbling skills, which requires a high level dynamic balance $[8,9,10]$. So, athletes' balance performance analyzing can be useful to investigate the role of specific factors on postural control [11]. Low balance ability is generally regarding an increased risk of ligament injuries [12, 13] and bilateral 
difference may be a contributing factor to injury and so the detection of a possible asymmetry in balance is important [14]. Some studies have reported an association between diminished balance and injury $[15,16,17]$. Two studies found no association $[18,19]$.

Coupled with motion and coordination between the ankle, knee, and hip joints, as well as motion at the trunk; dynamic balance tests require participants to demonstrate strength, flexibility, proprioception, and concentration [5]. In fact, the awareness of the center of mass control is important in sports [20]. When running at high speed, changing direction promptly and forcefully kick the ball to pass or shoot, soccer players must carry on balance. Moreover, they must maintain balance as opposing players try to impede them and steal the ball [6]. The appraisal and the periodic monitoring of static and dynamic balance in young athletes can be an important way to correctly define and update training programs, taking into account the sport practiced, the rate of improvement in balance scores over time. This would allow to maximize, in each period of the athlete's body development, the coherent creation and optimization of a wide set of fundamental motor abilities [11]. Quantitative analysis of postural sway revealed that soccer players present superior balance abilities compared with basketball players, swimmers and nonathletes for single leg stance [21, 22]. The balance control occurs three basic control inputs incorporated with the various sensor units: vestibular, visual and proprioceptive mechanoreceptors. Impaired stability control by disrupt the working sensory systems is one of the commonly used test procedures [23]. Therefore, the routine compares stability of the standing position in samples of the quiet standing with eyes open and closed [24]. Khuman, Kamlesh, Surbala (2014) found that the soccer players have a superior static and dynamic balance than cricket and volleyball players [4]. Also, Malliou, Gioftsidou, Pafis, Beneca, Godolias (2004) observed a positive development in the proprioception as compared to the results of specific balance exercises in healthy young soccer players [25].

Based on this information; It is important to determine the balance which is one of the important factors determining the performance in the soccer branch and to determine whether the soccer players have differentiated compared to the sedentary even though they have the same age group and similar physical characteristics. Therefore the hypothesis of this study was that the balance ability in soccer players would be better than sedentary. Hence the purpose of this study was to compare dynamic balance ability, y balance, flamingo balance among soccer players and sedentary.

\section{Materials and Methods}

\subsection{Participants}

Participants $(\mathrm{N}=34 ; 16$ soccer player, 18 sedentary; ages 13-14 yr) in secondary school. Soccer players participated soccer training for daily 2 hours and four days in a week for 3 years. No participant has had any medical condition or disability that limited participation in physical activity. Informed consent form signed by the entire participant, their parents and the trainer prior to the study. They gave their informed consent for the experimental procedure as required by the Helsinki declaration (2008). Data on anthropometric characteristics including age, body weight, height and body mass index (BMI) were obtained. The body height of the participants was measured using a metal scale with $0.1 \mathrm{~cm}$ sensitivity, and the body weight measurement was measured using a digital weight scale with $0.1 \mathrm{~kg}$ sensitivity. The participants' mean body height, body weight and BMI were $156.27 \mathrm{~cm}, 43.74 \mathrm{~kg}$ and $17.81 \mathrm{~kg} / \mathrm{m}^{2}$, respectively (Table 1 ).

\subsection{Measures}

Dynamic balance ability was measured by [Prokin Tecno Body, PKW 200 PL, Italy]. Easy type was used for bipedal, right and left foot dynamic balance. Participants' dynamic balance ability measured after providing the position of the equilibrium with bare feet and thin sportswear. The measurement repeated if participant fall over before the end of the test. Test was conducted twice for each participant. The rest duration for each measurement was 60 second. After the test there were 5 outcome and these were as following: 1) Perimeter Length (The number of total degrees done during the exercise), 2) Area Gap Percentage (The percentage of the area included in the drawn on flat view trace in respect to the reference circle), 3) Medium Speed (The average number of covered degrees for second), 4) Medium equilibrium centeranterior posterior axis (the average among the values reached on backward-forward axis), 5) Medium equilibrium center medium- lateral axis (the average among the values reached on medium- lateral axis.)

$Y$ balance was recorded as the tape measure fixed on the floor. Y balance test is another test that challenge an athlete's dynamic postural control system. The objective of the $y$ balance test is to maintain single-leg balance while reaching as far as possible with the contralateral leg in the anterior, posteromedial and posterolateral directions [5]. The starting position was standing on one leg at the stance point with the toes of the foot at the red line, and the other leg touching down lightly just behind the point. The non-stance foot was reached out in the desired direction, pushing the foot as far as they can while maintaining balance. The free foot must be returned to the starting position under control. The participant may not touch down the free leg during the movement to keep balance, or to gain support. Therefore there are six tests to be performed, in the following order: Right (anterior, posteriomedial, posteriolateral) reach and Left (anterior, posteriomedial, posteriolateral) reach. The maximal reach distance was measured by reading the tape measure at the point where the most distal part of the foot reached in half centimeters. Test was repeated two times, and the maximum reach in each direction was recorded. Each participant was barefoot during measurement. The rest duration between right and left foot measurement was 60 second.

Faigenbaum, Bagley, Boise, Farrel, Bates, and Myer 
(2015) compared performance on the Y balance test using a standard Y balance kit with a hand-made device in children [5]. Sixteen healthy children performed the y balance test using a standard $\mathrm{Y}$ balance kit and a handmade device on two nonconsecutive days. According to the results of the research, the dynamic balance performance of children in the standard $\mathrm{Y}$ balance kit is similar to that of a hand-made device [5]. So that, in this study hand made device used for measuring $\mathrm{Y}$ balance performance.

Flamingo singe leg test was recorded while standing on one leg with barefoot. While balancing on the preferred leg, the free leg was flexed at the knee. When the researcher started the watch the participant rose to the fingertips. Investigator stopped the stopwatch each time the participant loses balance. Each test was repeated two times for right-left foot eyes open and shut, and the maximum time in each direction was recorded. The rest duration for each measurement was 60 second. The Flamingo balance test (FBT) is a full body balance test that provides low cost and perfect conditions for mass investigations [26, 27].

\subsection{Statistical Analysis}

For statistical analyses; first of all normality test has been applied and identified that data has statistically normal distribution. Also partial eta squared was calculated as measures of effect size. For dynamic balance ability there were five different outcome (perimeter length, area gap percentage, medium speed, backward-forward medium equilibrium center, medium-lateral axis medium equilibrium center) and 3 level (bipedal, right foot, left foot). To understand whether there was a significant difference between dynamic balance ability and participating soccer training (between group) $3 \times 5 \times 2$ factorial ANOVA analysis was performed.

For $\mathrm{Y}$ balance measurement there were three different outcome (anterior, posteriomedial, posteriolateral) and 2 level (right foot, left foot). To understand whether there was a significant difference between $\mathrm{Y}$ balance measurement and participating soccer training (between group) $3 \times 2 \times 2$ factorial
ANOVA analysis was performed.

For Flamingo single leg test measurement there were two different outcome (eyes open, eyes shut) and 2 level (right foot, left foot). To understand whether there was a significant difference between flamingo single leg test measurement and participating soccer training (between group) $2 \times 2 \times 2$ factorial ANOVA analysis was performed.

Common effects were found significant and to understand these common effects post hoc analyses were performed. And then, to observe the significant difference between playing soccer and sedentary, independent t-test was applied.

\section{Results}

Descriptive statistics for physical characteristics as age, body height, body weight and BMI of Soccer players and sedentary were indicated in Table 1.

Table 1. Descriptive statistics of soccer players and sedentary.

\begin{tabular}{lllll}
\hline Variable & Groups & N & Mean & SD \\
\hline \multirow{2}{*}{ Age (years) } & Soccer Player & 16 & 13.56 & 0.51 \\
& Sedentary & 18 & 13.61 & 0.50 \\
Body Height $(\mathrm{cm})$ & Soccer Player & 16 & 157.81 & 6.63 \\
& Sedentary & 18 & 154.91 & 7.45 \\
Body Weight $(\mathrm{kg})$ & Soccer Player & 16 & 44.06 & 6.81 \\
& Sedentary & 18 & 43.46 & 7.03 \\
\multirow{2}{*}{ BMI $\left(\mathrm{kg} / \mathrm{m}^{2}\right)$} & Soccer Player & 16 & 17.58 & 1.50 \\
& Sedentary & 18 & 18.02 & 1.87 \\
\hline
\end{tabular}

$\mathrm{BMI}=$ Body Mass Index.

Soccer variable was entered as Between Group for soccer players and sedentary. Accordingly, the main effects were significant for dynamic balance ability on bipedal, right foot and left foot $[\mathrm{F}(2.256)=167.00, \mathrm{p}<0.05]$; soccer $\times$ dynamic balance $\left[\mathrm{F}(4.256)=5.887, \mathrm{p}<0.05\right.$, eta $\left.^{2}=0.155\right]$ and dynamic balance ability $\left[\mathrm{F} \quad(4.256)=668.61, \quad \mathrm{p}<0.05, \quad\right.$ eta $\left.^{2}=0.83\right]$. Common effects were significant for dynamic balance ability on levelXsoccer $\left[\mathrm{F} \quad(4.256)=5.88, \quad \mathrm{p}<0.05, \quad \mathrm{eta}^{2}=0.15\right]$; dynamicbalance $\times$ level $\left[\mathrm{F}(8.256)=203.31, \mathrm{p}<0.05\right.$, eta $\left.^{2}=0.86\right]$ and level $\times$ dynamicbalance $\times$ soccer $[\mathrm{F}(8.256)=3.72, \mathrm{p}<0.05$, eta $\left.^{2}=0.10\right)$ (Table 2).

Table 2. Descriptive statistics, independent samples t test, Cohens'd and Effect sizes for Prokin dynamic balance ability measurement.

\begin{tabular}{|c|c|c|c|c|c|c|c|c|c|}
\hline & & $\mathbf{N}$ & Mean & SD & $\mathbf{F}$ & $\mathbf{t}$ & Sig. (2-tailed) & Cohen's d & Effect Size \\
\hline Bipedal Perimeter Length & $\begin{array}{l}\text { SP } \\
\text { Sedant. }\end{array}$ & $\begin{array}{l}16 \\
18\end{array}$ & $\begin{array}{l}353.18 \\
437.68\end{array}$ & $\begin{array}{l}66.47 \\
120.89\end{array}$ & 3.847 & -2.479 & $0.019 *$ & -0.865 & -0.397 \\
\hline Bipedal Area Gap Percentage & $\begin{array}{l}\text { SP } \\
\text { Sedant. }\end{array}$ & $\begin{array}{l}16 \\
18\end{array}$ & $\begin{array}{l}9.85 \\
18.88\end{array}$ & $\begin{array}{l}6.91 \\
13.12\end{array}$ & 13.643 & -2.462 & $0.019 *$ & -0.861 & -0.395 \\
\hline Bipedal Medium Speed & $\begin{array}{l}\text { SP } \\
\text { Sedant. }\end{array}$ & $\begin{array}{l}16 \\
18\end{array}$ & $\begin{array}{l}11.79 \\
14.20\end{array}$ & $\begin{array}{l}2.20 \\
3.75\end{array}$ & 2.296 & -2.241 & $0.032 *$ & -0.783 & -0.364 \\
\hline $\begin{array}{l}\text { Bipedal Medium Equilibrium } \\
\text { Center- Forward backward axis }\end{array}$ & $\begin{array}{l}\text { SP } \\
\text { Sedant. }\end{array}$ & $\begin{array}{l}16 \\
18\end{array}$ & $\begin{array}{l}-0.40 \\
-1.29\end{array}$ & $\begin{array}{l}1.82 \\
2.06\end{array}$ & 0.87 & 1.32 & 0.19 & $0.457 \phi$ & 0.223 \\
\hline $\begin{array}{l}\text { Bipedal Medium Equilibrium } \\
\text { Center-Medium lateral axis }\end{array}$ & $\begin{array}{l}\text { SP } \\
\text { Sedant. }\end{array}$ & $\begin{array}{l}16 \\
18\end{array}$ & $\begin{array}{l}-0.82 \\
-1.94\end{array}$ & $\begin{array}{l}1.81 \\
2.55\end{array}$ & 0.50 & 1.45 & 0.15 & $0.506 \phi$ & 0.245 \\
\hline Right Perimeter Length & $\begin{array}{l}\text { SP } \\
\text { Sedant. }\end{array}$ & $\begin{array}{l}16 \\
18\end{array}$ & $\begin{array}{l}136.68 \\
177.36\end{array}$ & $\begin{array}{l}37.97 \\
64.21\end{array}$ & 3.27 & -2.21 & $0.03 *$ & -0.771 & -0.359 \\
\hline Right Area Gap Percentage & $\begin{array}{l}\text { SP } \\
\text { Sedant. }\end{array}$ & $\begin{array}{l}16 \\
18\end{array}$ & $\begin{array}{l}-0.18 \\
3.93\end{array}$ & $\begin{array}{l}3.36 \\
10.52\end{array}$ & 5.21 & -1.49 & 0.14 & -0.526 & -0.254 \\
\hline Right Medium Speed & $\begin{array}{l}\text { SP } \\
\text { Sedant. }\end{array}$ & $\begin{array}{l}16 \\
18\end{array}$ & $\begin{array}{l}13.66 \\
17.91\end{array}$ & $\begin{array}{l}3.79 \\
6.61\end{array}$ & 4.22 & -2.25 & $0.03 *$ & -0.788 & -0.366 \\
\hline Right Medium Equilibrium & SP & 16 & -1.25 & 1.79 & 0.32 & -1.08 & 0.28 & -0.377 & -0.185 \\
\hline
\end{tabular}




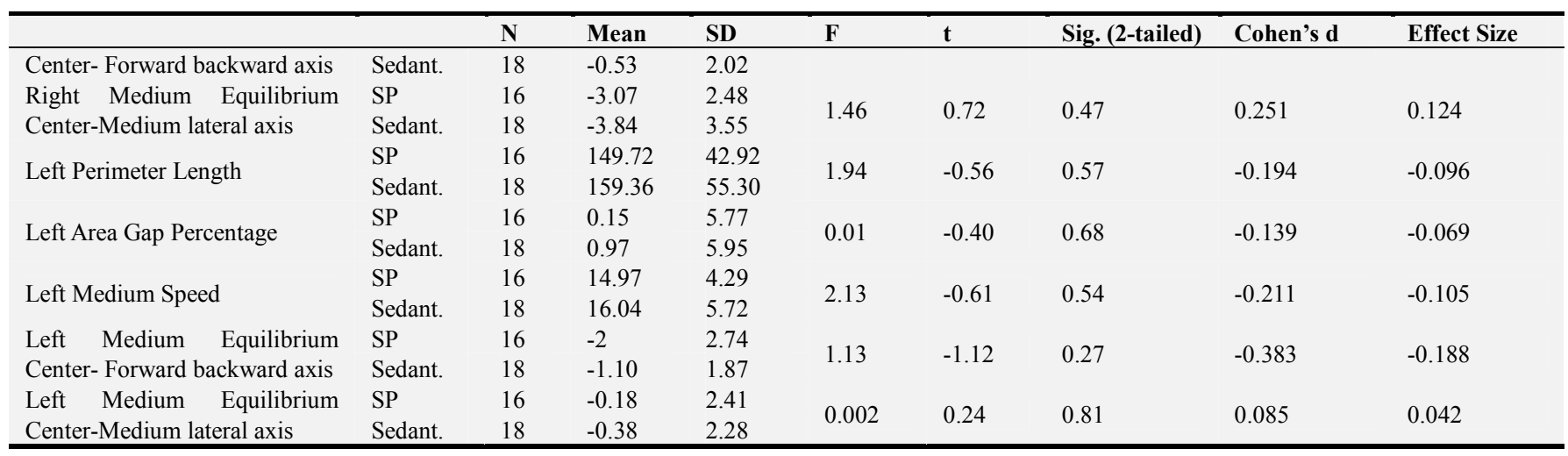

$\mathrm{p}<0.05, \mathrm{SP}=$ Soccer Player, Sedant. $=$ Sedentary, Effect size, Cohen's $d .{ }^{\phi} p<0.05$.

As shown in Table 2; the mean values are clearly different in soccer players than sedentary in favor of soccer players (Table 2).

The effect of playing soccer on y balance were significant; soccer $\times$ ybalance $[\mathrm{F}(2.64)=10.734, \mathrm{p}<0.05$, eta $2=0.251]$ and for $y$ balance $[F(2.64)=11.40, p<0.05$, eta $2=0.263]$. Common effects on level $\mathrm{X}$ soccer of $\mathrm{y}$ balance was not significant $[\mathrm{F}$ $(1.64)=0.337, \mathrm{p}>0.05$, eta $2=0.01]$. Common effects on ybalance $\times$ level $[\mathrm{F}(2.64)=0.174, \mathrm{p}>0.05$, eta2 $=0.251]$ and level $\times$ ybalance $\times$ soccer $\quad[\mathrm{F} \quad(82.64)=0.586, \quad \mathrm{p}>0.05$, eta $2=0.018$ ) were significant (Table 3 ).

Table 3. Descriptive statistics, independent samples t test, Cohens'd and Effect sizes for Y Balance Test Measurement.

\begin{tabular}{|c|c|c|c|c|c|c|c|c|c|}
\hline & & $\mathbf{N}$ & Mean & SD & $\mathbf{F}$ & $\mathbf{t}$ & Sig. (2-tailed) & Cohen's d & Effect Size \\
\hline \multirow{2}{*}{ Right Anterior (cm) } & SP & 16 & 74.34 & 6.52 & \multirow{2}{*}{0.66} & \multirow{2}{*}{3.65} & \multirow{2}{*}{$0.001^{*}$} & \multirow{2}{*}{$1.263 \phi$} & \multirow{2}{*}{0.534} \\
\hline & Sedant. & 18 & 65.33 & 7.68 & & & & & \\
\hline \multirow{2}{*}{ Right Posteriomedial $(\mathrm{cm})$} & SP & 16 & 75.56 & 6.54 & \multirow{2}{*}{2.76} & \multirow{2}{*}{0.44} & \multirow{2}{*}{0.66} & \multirow{2}{*}{0.153} & \multirow{2}{*}{0.0767} \\
\hline & Sedant. & 18 & 74.16 & 11.03 & & & & & \\
\hline \multirow{2}{*}{ Right Posteriolateral (cm) } & SP & 16 & 78.03 & 5.02 & \multirow{2}{*}{6.97} & \multirow{2}{*}{3.52} & \multirow{2}{*}{$0.001 *$} & \multirow{2}{*}{$1.233 \phi$} & \multirow{2}{*}{0.524} \\
\hline & Sedant. & 18 & 68.38 & 9.84 & & & & & \\
\hline Left Anterior $(\mathrm{cm})$ & SP & 16 & 75.18 & 6.34 & 4.41 & 3.56 & $0.001^{*}$ & $1.241 \phi$ & 0.527 \\
\hline \multirow{2}{*}{ Left Posteriomedial $(\mathrm{cm})$} & SP & 16 & 74.75 & 9.30 & \multirow{2}{*}{0.73} & \multirow{2}{*}{-0.26} & \multirow{2}{*}{0.78} & \multirow{2}{*}{-0.092} & \multirow{2}{*}{-0.046} \\
\hline & Sedant. & 18 & 75.55 & 8.14 & & & & & \\
\hline \multirow{2}{*}{ Left posteriolateral $(\mathrm{cm})$} & SP & 16 & 78.25 & 6.37 & \multirow{2}{*}{3.45} & \multirow{2}{*}{2.80} & \multirow{2}{*}{$0.008^{*}$} & \multirow{2}{*}{$0.975 \phi$} & \multirow{2}{*}{0.438} \\
\hline & Sedant. & 18 & 70.44 & 9.35 & & & & & \\
\hline
\end{tabular}

$* \mathrm{p}<0.05, \mathrm{SP}=$ Soccer Player, Sedant. $=$ Sedentary, Effect size, Cohen's d. $\phi \mathrm{p}<0.001$.

The mean and standard deviation values are given for $\mathrm{y}$ balance measurements for soccer players and sedentary (Table 3).

The effect of playing soccer on flamingo balance was significant; soccer X Flamingo balance $[\mathrm{F}(1.32)=26.20$, $\mathrm{p}<0.05$, eta $\left.{ }^{2}=0.450\right]$ and for flamingo balance $[\mathrm{F}$ $(1.32)=62.532, \quad \mathrm{p}<0.05$, eta $\left.^{2}=0.661\right]$. Common effects on level $\times$ soccer of flamingo balance $[\mathrm{F}(1.32)=0.448, \mathrm{p}>0.05$, eta $\left.^{2}=0.01\right]$ and flamingo balance $\times$ level $[\mathrm{F}(1.32)=1.256$, $\mathrm{p}>0.05, \quad$ eta $\left.^{2}=0.038\right] \quad$ and level $\times$ balance $\times$ soccer $\quad[\mathrm{F}$ $(1.32)=0.008, \quad \mathrm{p}>0.05$, eta ${ }^{2}=0.000$ ] were not statistically significant (Table 4).

To observe significant differentiation between soccer players and sedentary independent $\mathrm{t}$ test was used.

Table 4. Descriptive statistics, independent samples t test, Cohens'd and Effect sizes for flamingo single leg measurement.

\begin{tabular}{|c|c|c|c|c|c|c|c|c|c|}
\hline & & $\mathbf{N}$ & Mean & SD & $\mathbf{F}$ & $\mathbf{t}$ & Sig. (2-tailed) & Cohen's d & Effect Size \\
\hline \multirow{2}{*}{ On Right Foot Eyes Opened (sn) } & SP & 16 & 18.01 & 11.73 & \multirow{2}{*}{9.94} & \multirow{2}{*}{4.33} & \multirow{2}{*}{$0.000^{*}$} & \multirow{2}{*}{$1.454 \phi$} & \multirow{2}{*}{0.588} \\
\hline & Sedant. & 18 & 5.21 & 4.16 & & & & & \\
\hline \multirow{2}{*}{ On Right Foot Eyes Closed (sn) } & $\mathrm{SP}$ & 16 & 3.35 & 1.61 & \multirow{2}{*}{19.92} & \multirow{2}{*}{4.80} & \multirow{2}{*}{$0.000 * *$} & \multirow{2}{*}{$1.605 \phi$} & \multirow{2}{*}{0.625} \\
\hline & Sedant. & 18 & 1.45 & 0.46 & & & & & \\
\hline \multirow{2}{*}{ On Left Foot Eyes Opened (sn) } & SP & 16 & 16.02 & 8.45 & \multirow{2}{*}{21.23} & \multirow{2}{*}{5.79} & \multirow{2}{*}{$0.000 * *$} & \multirow{2}{*}{$1.937 \phi$} & \multirow{2}{*}{0.695} \\
\hline & Sedant. & 18 & 3.97 & 2.41 & & & & & \\
\hline On Left Foot Eyes Closed (sn) & SP & 16 & 2.66 & 0.94 & 1.56 & 3.51 & $0.001 * *$ & $1.188 \phi$ & 0.510 \\
\hline
\end{tabular}

${ }^{* *} \mathrm{p}<0.001, \mathrm{SP}=$ Soccer Player, Sedant.= Sedentary, Effect size, Cohen's $d .{ }^{\phi} p<0.001$.

In table 4, soccer players' flamingo measurement results show that soccer players' values are clearly different from sedentary.
As shown in Table 2 according to the results of Independent samples $t$ test; bipedal and right foot perimeter length, bipedal area gap percentage, bipedal and right foot 
medium speed were statistically significant. In Table 3, for y balance test; right-left anterior, right-left posteriolateral results were found statistically different $(\mathrm{p}<0.05)$ (Table 3$)$. And finally the effect of playing football for flamingo balance test in Table 4, both eyes open and shut on right and left foot were statistically significant $(\mathrm{p}<0.05)$.

\section{Discussion}

The main purpose of the present study was to investigate differences in different measured balance abilities between soccer players and sedentary. The results of this research suggest that the repeated habit of training and playing soccer appears to influence the effectiveness of the balance. In balance testing with the Prokin, core stability plays an important role because the person has to maintain the equilibrium on an instable plate. In literature review, there have done lots of study about the balance differences between the different sport branches and sedentary people, nevertheless very few studies comparing the values of dynamic and static balance $[4,9,27,28,29]$. Similar to our results; Davlin (2004) found that the dynamic balance values of athletes were superior to the values of sedentary people [10]. In addition Gökdemir, Ciğerci, Suveren, Sever (2012) found that the balance values of sedentary people were lower than the values of athletes [27]. Their study intended for describing the static and dynamic balance of female basketball, football, volleyball players and sedentary people. Bressel et al (2007) have indicated that athletes who were professionalized in bipedal stance required sports are superior to others who were generally unipedal-required sports. Soccer requires bipedal stance in competition, however frequency is different [9]. According to this; in this study bipedal perimeter length values were significantly different in soccer players when compared to sedentary. Paillard and Noe (2006) compared amateur and national level soccer players and found that amateur level players were inferior in both active and blocked conditions of visual system in terms of center of mass [30]. Paillard, Noe, Riviere, Marion, Montoya, Dupui (2006) indicated the source of the difference among elite and non-elite soccer players and it was the level of athlete. Due to training athletes become more independent to visual system during postural control [31]. Therefore balance ability is one of the most important and precise components for extricating amateurs from professionals. When the results of this study were carefully examined, it was revealed that the soccer players perform better performance than sedentary for the balance ability.

The results of current study were in accordance with studies of Gökdemir et. al (2012), Bressel, Yonker, Kras and Heath (2007), Kesilmiş \& Akın (2015) [9, 27, 29]. Hatzitaki, Zlsi, Kollias and Kioumourtzoglou (2002) determined that children aged 11 to 13 can apply strategies that are significantly similar to the strategies that adults use to maintain balance under static or dynamic conditions [32]. Hrysomallis (2011) reported that when soccer was compared to other athletes, balance performance is the second best after gymnasts [33]. This is reported to be caused by the repeated position of the soccer players to maintain balance on one leg while kicking the ball. Bakhtiari (2012) measured the maximum duration that the classic flamingo balance position could be held and assessed the static and dynamic balance and the knee proprioception of thirty-six young male professional soccer players. Then, the static balance performances of soccer players were compared with the results of a Star Excursion Balance Test. The results were significantly different between static balance with open eyes and close eyes [26]. In addition it was also shown that standing with eyes open differs significantly from standing with eyes closed $[34,35]$. In this study, both eyes open balance performances differ significantly from eyes closed balance performances, and soccer players perform superiorly than sedentary in both cases. Similar to present study; In a study comparing the balance parameters of two groups playing and nonplaying soccer, Sucan, Yılmaz, Can, Süer (2005) have determined that all balance parameters differ in favor of soccer players, and this was explained in that football players can control better the physiological system that provides balance [36]. Providing the balance is a significant contribution of the lower extremity stabilizer muscles. Strengthening of these muscles can be said to be effective in the development of balance ability [37]. Kligyt, Ekman, Medeiros (2003) reported that the weakness of the lower extremity muscle strengths had adverse effects on the dynamic balance. If it is considered that the lower extremity strength is developed in football players, it can be considered that one of the causes of the low balance scores of the sedans is also the force [38]. In contrast to present study, Gioftsidou, Malliou, Pafis, Beneka, Godolias, and Maganaris (2006) found no differences in static balance abilities in young players before and after a soccer training session [39].

According to the results of this present study, it can be concluded that sport participation would significantly improve balance ability of participants. These findings can be the results of regularly participate in soccer trainings and competitions. Due to the popularity of soccer and the tremendous supply of participants of this sport in one hand, and the major role of balance in sports specially in soccer, and the truth that human being are bipeds and daily life activities which causes a critical challenge to our balance system on the other hand, this study proposed that sport participation would significantly improve balance ability of participants. In this research; the better balance performances of soccer players versus sedentary may be the reason of regular trainings affect on the psychomotor responses of them. The statistically non-significant results of the current study may also be the result of the amateur level of the athletes. It is suggested that future study in this field conducted with a larger sample size and in different athletes.

\section{Conclusion}

Soccer is one of the sports branches, where need balance performance and necessitating the use of the lower 
extremity. The current study results suggest that regular soccer training improves balance ability in prepubertal boys. Although they have similar physical characteristics, soccer players perform better in bipedal perimeter length, bipedal medium speed, bipedal area gap percentage, right perimeter length, right medium speed, right-left anterior, right-left posteriolateral, and flamingo single length measurements than sedentary. It has been reached as a result of the contribution of soccer training to balance ability, which is important for every age group and is an indispensable part of everyday life.

\section{References}

[1] Malina RM, Bouchard C. Growth, maturation, and physical activity. Human Kinetics Books Champaign, Illinois, 1991; $2^{\text {nd }}$ edition, p.217-224.

[2] Gualtieri D, Cattaneo A, Sarcinella R, Cimadoro G, Alberti G. Relationship between balance capacity and jump ability in amateur soccer players of different ages. Sport Sci Health $2008 ; 3: 73-76$.

[3] Akman N, Karataş M. Temel ve Uygulanan Kinesyoloji, Haberal Eğitim Vakfi, Ankara, 2003; pp 247-288.

[4] Khuman PR, Kamlesh T, Surbala L. Comparison of static and dynamic balance among collegiate cricket, soccer and volleyball male players. International Journal of Health \& Allied Sciences 2014; 3(1): 9-13.

[5] Faigenbaum AD, Bagley J, Boise S, Farrel A, Bates N, Myer GD. Dynamic balance in children: Performance comparison between two testing devices. Athletic Training \& Sports Health Care 2015; 7(4): 160-164.

[6] Gerbino PG, Griffin ED, Zurakowski D. Comparison of standing balance between female dancers and soccer players. Gait \& Posture 2007; 26(4): 501-507.

[7] Evangelos B, Georgios K, Konstantınos A, Gissis I, Papadopoulos C, Aristomenis S. Proprioception and balance training can improve amateur soccer players' technical skills. Journal of Physical Education and Sport 2012; 12(1): 81-89.

[8] Orchard J. Is there a relationship between ground and climatic conditions and injuries in football? Sports Med 2002; 32(7): 419-432.

[9] Bressel E, Yonker JC, Kras J, Heath EM. Comparison of static and dynamic balance in female collegiate soccer, basketball, and gymnastics athletes. Journal of Athletic Training 2007; 42(1): 42-46.

[10] Davlin CD. Dynamic balance in high level athletes. Perceptual \& Motor Skills 2004; 98(3): 1171-1176.

[11] Ricotti L. Static and dynamic balance in young athletes. Journal of human sport \& exercise 2011; 6(4): 616-628.

[12] Hrysomallis C, Mclaughlin P, Goodman C. Balance and injury in elite Australian footballers. International Journal of Sports Medicine 2007; 28(10): 844-847.

[13] Caraffa A, Cerulli G, Projetti M, Aisa G, Rizzo A. Prevention of anterior cruciate ligament injuries in soccer: A prospective controlled study of proprioceptive training. Knee Surgery,
Sports Traumatology, Arthroscopy 1996; 4(1): 19-21.

[14] Gstöttner M, Neher A, Scholtz A, Millonig M, Lembert S, Raschner C. Balance ability and muscle response of the preferred and nonpreferred leg in soccer players. Motor Control 2009; 13(2): 218-231.

[15] Mcguine TA, Greene JJ, Best T, Leverson G. Balance as a predictor of ankle injuries in high school basketball players. Clin J Sport Med 2000;10(4):239-244.

[16] Soderman K, Alfredson H, Pietila T, Werner S. Risk factors for leg injuries in female soccer players:a prospective investigation during one out-door season. Knee Surg. Sports Traumatol Arthrosc 2001; 9(5): 313-321.

[17] Tropp H, Ekstrand J, Gillquist J. Stabilometry in functional instability of the ankle and its value in predicting injury. Med Sci Sports Exerc 1984; 16 (1): 64-66.

[18] Beynnon BD, Murphy DF, Alosa DM. Predictive factors for lateral ankle sprains: A Literature Review. Journal of Athletic Training 2002; 37(4): 376-380.

[19] Hopper DM, Hopper JL, Elliot, BC. Do selected kinanthropometric and performance variables predict injuries in female netball players? Journal of Sport Sciences 1995; 13(3): 213-222.

[20] Zemková E. Assessment of balance in sport: Science and reality. Serbian Journal of Sports Sciences 2011; 5(1-4): 127139.

[21] Matsuda S, Demura S, Uchiyama M. Center of pressure sway characteristics during static one-legged stance of athletes from different sports. Journal Sport Sciences 2008; 26: 775-779.

[22] Matsuda S, Demura S, \& Demura T. Examining differences between center of pressure sway in one-legged and twolegged stances for soccer players and typical adults. Perceptual and Motor Skills 2010; 110: 751-760.

[23] Błaszczyk JW, Beck M, Sadowska D. Assessment of postural stability in young healthy subjects based on directional features of posturographic data: Vision and gender effects. Acta Neurobiology Exp. 2014; 74: 433-442.

[24] Duarte M, Zatsiorsky VM. Effects of body lean and visual information on the equilibrium maintenance during stance. Exp Brain Res 2002; 146: 60-69.

[25] Malliou P, Gioftsidou A, Pafis G, Beneka A, Godolias G. Proprioseptif training (balance exercises) reduces lower extremity injuries in young soccer players. Journal of Back and Musculoskeletal Rehabilitation 2004; 17: 101-104.

[26] Bakhtiari RA. Evaluation of static and dynamic balance and knee proprioception in young professional soccer players. Annals of Biological Research 2012; 3(6): 2867-2873.

[27] Gökdemir K, Ciğerci AE, Er F, Suveren C, Sever O. The comparison of dynamic and static balance performance of sedentary and different branches athletes. World Applied Sciences Journal 2012; 17(9): 1079-1082.

[28] Karadenizli Zİ, Erkut O, Ramazanoğlu N, Uzun S, Camlıgüney AF, Bozkurt S, Tiryaki C, Küçük V, Sirmen B. Comparision of dynamic and static balance in adolescents handball and soccer players. Turkish Journal of Sport and Exercise 2014; 16(1): 47-54. 
[29] Kesilmiș İ, Akın M. [The effect of gymnastics trainin on biomotor abilities in four-six years of age children]. Turkiye Klinkleri J Sports Sci 2016; 8(1): 15-21.

[30] Paillard T, Noe F. Effect of expertise and visual contribution on postural control in soccer. Scand J Med Sci Sports 2006; 16(5): 345-348.

[31] Paillard T, Noe F, Riviere T, Marion V, Montoya R, Dupui P. Postural performance and strategy in the unipedal stance of soccer players at different levels of competition. Journal of Athletic Training 2006; 41(2): 172-176.

[32] Hatzitaki V, Zlsi I, Kollias I, Kioumourtzoglou E. Perceptualmotor contributions to static and dynamic balance control in children. Journal of Motor Behavior 2002; 34(2): 161-170.

[33] Hrysomallis, C. Balance ability and athletic performance. Sports Medicine 2001; 41(3): 221-232.

[34] Collins J. J the effects of visual input on open-loop and closeloop postural control mechanism. Exp. Brain Res. 1995; 103:151-163.
[35] Błaszczyk J. W., Lowe D. J., Hansen P. D. Postural sway and perception of the upright stance stability borders. Acta Neurobiology 1997; 57: 49-57.

[36] Sucan S, Y1lmaz A, Can Y, Süer C. The Different Balance Parameters Evaluation of the Active Soccer Players. Journal of Health Sciences 2005; 14(1) 36-42.

[37] Malliou P, Ispirlidis I, Beneka A, Taxildaris K, Godolias G. Vertical jump and knee extensors isokinetic performance in professional soccer players related to the phase of the training period. Isokinetics And Exercise Science, 2003; 11: 165-169.

[38] Kligytė I, Ekman LL, Medeiros JM. Relationship between lower extremity muscle strength and dynamic balance in people post-stroke. Medicina 2003; 39(2): 122-128.

[39] Gioftsidou A, Malliou P, Pafis G, Beneka A, Godolias G, \& Maganaris CN. The effects of soccer training and timing of balance training on balance ability. European Journal of Applied Physiology 2006; 96(6): 659-664. 